\title{
Same-session salvage endoscopic submucosal dissection for an incompletely resected rectal neuroendocrine tumor
}

A 61-year-old gentleman was referred for a rectal subepithelial lesion identified incidentally during screening colonoscopy. Lower endoscopic ultrasound demonstrated a $10-\mathrm{mm}$ submucosal lesion $5 \mathrm{~mm}$ in thickness with well-defined borders not invading the muscularis propria ( $\triangleright$ Fig. 1). Endoscopic mucosal resection (EMR) was performed with adequate submucosal lift (\Fig.2); however, hot snare resection transected the lesion with obvious residual yellow tissue within the submucosa ( $\triangleright$ Fig. 3 ).

The procedure was immediately converted to endoscopic submucosal dissection (ESD) using a hook knife (Olympus America, Center Valley, Pennsylvania, USA) $(\triangleright$ Video 1$)$. The lesion had an intact capsule at the lateral and deep margins ( $\triangleright$ Fig.4). The final resection site demonstrated no macroscopic residual disease and required 33 minutes for ESD ( Fig.5). Histological examination revealed a grade 1 well-differentiated neuroendocrine tumor (NET) involving the mucosa and submucosa without evidence of lymphovascular invasion and a Ki-67 index of $1 \%$. The peripheral and deep resection margins were negative for tumor. The patient reported no adverse events at 4-week follow-up.

Small rectal NETs localized to the mucosa or submucosa can be treated with endoscopic resection [1]. Superficial rectal NETs smaller than $1 \mathrm{~cm}$ are often managed with EMR. However, there are currently no widely used guidelines regarding the management of rectal NETs 10$20 \mathrm{~mm}$ in diameter [2-5].

In this case, although the lesion was small, the submucosal involvement resulted in incomplete resection with EMR despite adequate lifting. This highlights that if recognized ahead of time, even small lesions involving the submucosa should be considered for upfront ESD. However, if EMR is attempted and results in incomplete resection, same-session conversion to ESD is feasible. This pre-

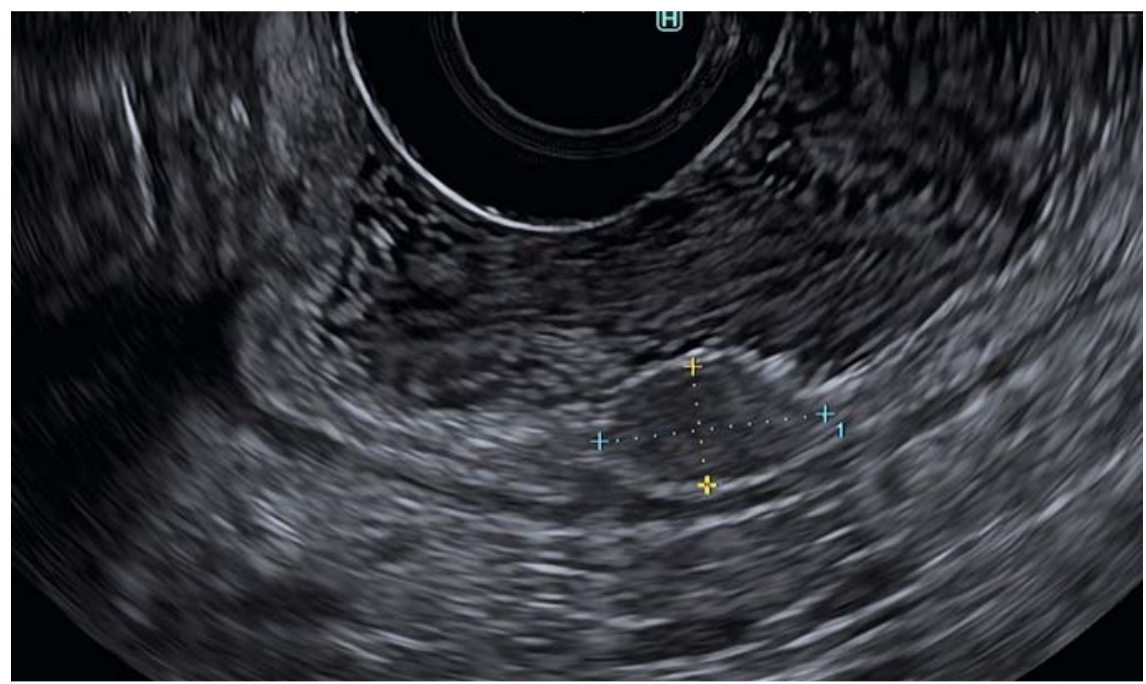

- Fig. 1 Lower endoscopic ultrasound image showing a rectal hypoechoic lesion involving the superficial submucosa.

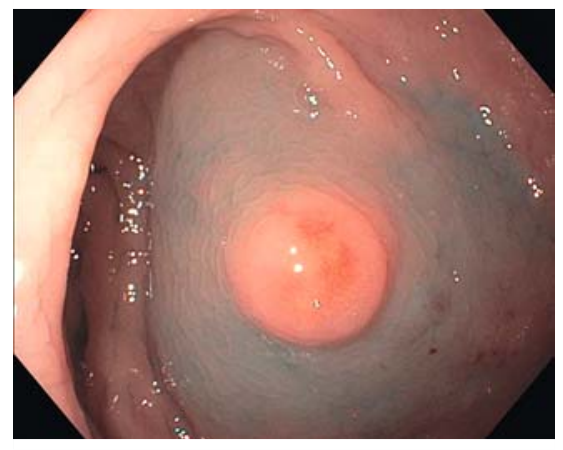

- Fig. 2 Adequate lifting of the subepithelial lesion after submucosal injection.

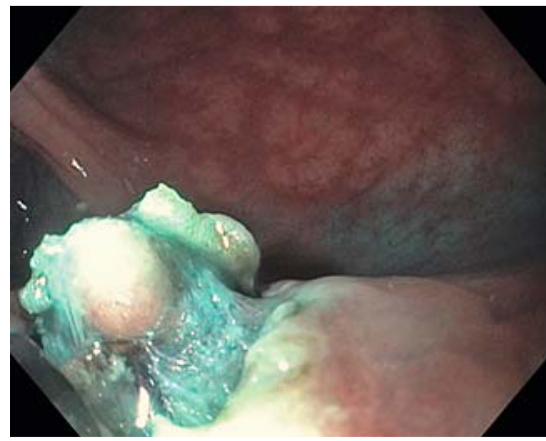

- Fig. 4 Endoscopic submucosal dissection (ESD) of the residual lesion demonstrating an intact capsule at the lateral and deep margins.

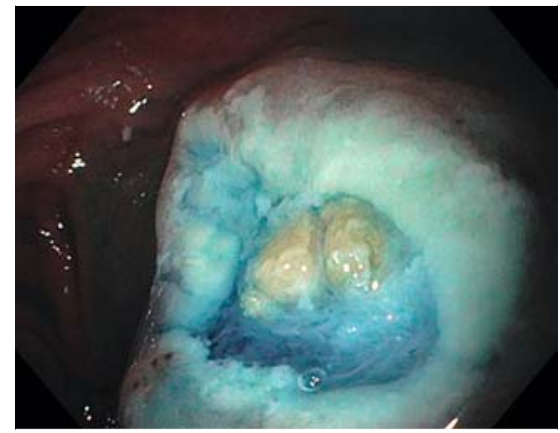

- Fig. 3 Incomplete resection of the rectal subepithelial after endoscopic mucosal resection.

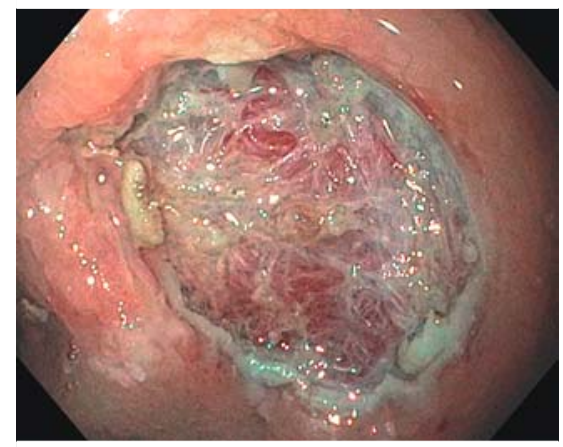

- Fig. 5 Resection site demonstrating no macroscopic residual disease after salvage ESD. 


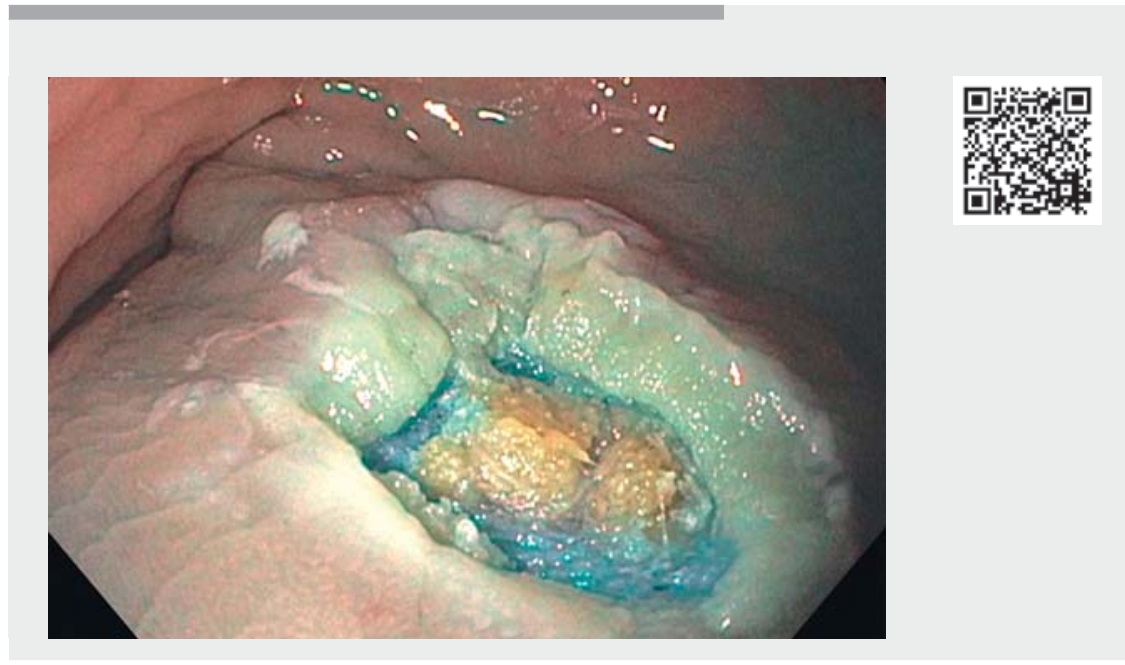

$\checkmark$ Video 1 Same-session salvage endoscopic submucosal dissection for an incompletely resected rectal neuroendocrine tumor.

vents the need for a second procedure and another sedation and allows for performance of submucosal dissection of relatively normal tissue. Delayed ESD is tedious owing to the robust submucosal fibrosis that may occur after hot snare resection.

Endoscopy_UCTN_Code_CPL_1AJ_2AD

Competing interests

Dr. Chandrasekhara is a shareholder for Nevakar Corporation and is on the advisory board of Interpace Diagnostics. He is a consultant for Covidien LP.

The authors

Vishal Garimella, Vinay Chandrasekhara Department of Gastroenterology and Hepatology, Mayo Clinic, Rochester, Minnesota, USA
Corresponding author

\section{Vinay Chandrasekhara, MD}

Department of Gastroenterology and Hepatology, Mayo Clinic, 200 First Street SW, Rochester, MN 55905, USA

Chandrasekhara.vinay@mayo.edu

\section{References}

[1] Anthony LB, Strosberg JR, Klimstra DS et al. The NANETS consensus guidelines for the diagnosis and management of gastrointestinal neuroendocrine tumors (NETs): welldifferentiated NETs of the distal colon and rectum. Pancreas 2010; 39: 767-774

[2] Choi HH, Kim JS, Cheung DY et al. Which endoscopic treatment is the best for small rectal carcinoid tumors? World J Gastrointest Endosc 2013; 5: 487-494

[3] Kim J, Kim JH, Lee JY et al. Clinical outcomes of endoscopic mucosal resection for rectal neuroendocrine tumor. BMC Gastroenterol 2018; 18: 77

[4] Park HW, Byeon JS, Park YS et al. Endoscopic submucosal dissection for treatment of rectal carcinoid tumors. Gastrointest Endosc 2010; 72: 143-149

[5] Lee DS, Jeon SW, Park SY et al. The feasibility of endoscopic submucosal dissection for rectal carcinoid tumors: comparison with endoscopic mucosal resection. Endoscopy 2010; 42: 647-651

\section{Bibliography}

Endoscopy 2022; 54: E598-E599

DOI 10.1055/a-1694-3367

ISSN 0013-726X

published online 21.12.2021

(C) 2021. Thieme. All rights reserved.

Georg Thieme Verlag KG, Rüdigerstraße 14, 70469 Stuttgart, Germany

\section{ENDOSCOPY E-VIDEOS}

https:|/eref.thieme.de/e-videos 